\title{
MAIN FACTORS AFFECTING MARE INSEMINATION WITH CRYOPRESERVED DOMESTIC AND FOREIGN SPERM
}

\section{L.F. LEBEDEVA, M.M. ATROSHCHENKO, S.A. BURMISTROVA}

All-Russian Research Institute for Horse Breeding, Divovo, Rybnoe Region, Ryazan Province, 391105 Russia, e-mail vniik08@mail.ru, Lebedeva-L18@yandex.ru

Received May 19, 2015

\section{Abstract}

Artificial insemination (AI) has the following advantages over natural mating: fast selection effect, easy transportation, wide dissemination of valuable genetic material, economic use of semen and rational use of sires, preventing sexually transmitted infections, reserving sperm in cryobanks. Among the factors influencing the result of AI in horse breeding are time, frequency rate and insemination repetition, quality and quantity of semen, the depth of insertion of semen into the uterus of a mare, the observance of temperature mode and sanitary regulations during AI procedure, the reproductive performance of mares. There are two main approaches to freezing of stallion sperm and thus two AI technologies for semen packaging and equipment for its introduction into the uterus of mares. The first approach worked out and used in Russia is based on a sparing mode of semen cryopreservation in large volumes, 20-25 $\mathrm{ml}$ per dose. The second method, developed abroad, provides pre-treatment of sperm by centrifugation and maximum removal of semen plasma. In another procedure currently used in Russia the small volumes $(5-6 \mathrm{ml})$ of semen are cryopreserved after centrifugation, removal of 50-60\% of semen plasma and thickening semen by dialysis. In recent years frozen semen of stallions from Europe and America is being actively imported to Russia. Despite the technological differences, domestic and foreign approaches to the cryopreservation of stallion's semen provide its similar qualitative characteristics after thawing. The aim of our research was to identify the most significant factors affecting pregnancy rates in artificially inseminated mares when domestic and foreign protocols were used to freeze sperm. Herein, an impact of five such factors (i.e. sperm packing/cryopreservation technology, time of insemination, reproductive state and gynecological soundness of the mares, the activity of sperm) on the effectiveness of AI with frozen semen was estimated in mares of various breeds (Arabian, Akhal-Teke, Trakehner, Hanoverian, Russian Riding horse, American Standardbred, Russian Trotter and Orlov Trotter). Experiments were carried out in 2012 to 2014 at Tersk stud, at a private farm (Mr. A.A. Kazakov the owner) and at experimental stable of the All-Russian Research Institute for Horse Breeding. We compared the data on 106 estrus cycles of 53 mares, artificially inseminated with domestic (granules and tubes of $5 \mathrm{ml}$ and $15-25 \mathrm{ml})$ and foreign frozen semen $(0.5 \mathrm{ml}$ in straws). All used sperm doses in various packages were divided into two groups with the activity above and below 1.5 points $(15 \%)$. The time recommended for AI with frozen semen was divided into three intervals ( $12 \mathrm{~h}$ before ovulation, during ovulation, $6 \mathrm{~h}$ after ovulation). The animals were conventionally grouped as barren and maiden mares, lactating mares, mares after late ( 6 or more months of pregnancy) abortion, and also with regard to absence or presence of gynecological pathologies such as vaginal discharge, fluid and air in the uterus, mating-induced endometritis. The effectiveness of artificial insemination was evaluated with regard to pregnancy rate, occurred abortions number and successful foaling. So, two of five factors analyzed were found out to determine reliably a successful AI with frozen semen at high significance level $(\mathrm{p}<0.001)$. They were the sperm activity of $\geq 15 \%$ and healthy mares with no pathology observed. Cryopreservation technology, the type of sperm doses' packaging and also the mare's reproductive status (i.e. barren, maiden, lactating or after late abortion) are of secondary importance. It is shown that mares' artificial insemination with one dose of semen during the 6-hour period after ovulation provides the same pregnancy rate $(67.7 \%)$ as insemination during the 12-hour period before ovulation $(65.0 \%)$ or insemination at the time when the ovum is released from a follicle.

Keywords: mare, sperm, cryopreservation, artificial insemination.

Attempts to fertilize females by transferring male sperm into their reproductive tracts have been made by ancient Assyrians (1000 BC). However, this technique reached the scope of zootechnical production method in animal hus- 
bandry only at the beginning of the last century thanks to I.I. Ivanov [1]. The contribution of Russian and Soviet scientists in the world practice of artificial insemination (AI) of farm animals is enormous. The names of V.K. Milovanov, A.V. Kvasnitsky, I.I. Sokolovskaya, and I.V. Smirnov are well known abroad. Scientific publications and achievements of the All-Union (now All-Russian) Institute of Horse Breeding (Breeding Institute) on AI and cryopreservation of stallion semen make up the golden fund of domestic science, are marked by state awards and are among the world's priorities. In 1954, P.N. Skatkin and his student T.P. Il'inskaya obtained the world's first foals from frozen semen; V.G. Parshutina and E.S. Kruzhkova (1956), V.A. Rumyantseva (1958), E.M. Platova and S.Ya. Rombe (1967), A.I. Naumenkova and N.K. Roman'kova (1969) conducted studies on the selection of composition of diluents, cryoprotectants, refrigerants, methods of packing and processing regimes for stallion semen to ensure its fertilizing capacity and maximum storage time [2, 3]. In the 1970s, the Cryobank was established at the Research Institute of Horse Breeding which currently holds about 3,000 doses of semen of outstanding stallions of 15 horse breeds. It should be emphasized that such a record time of stallions' semen storage has not been reported wherever in the world yet. Periodic inspections of fertilizing capacity and obtaining progeny from the semen stored in liquid nitrogen for $16,25,30,33,35$, and 38 years prove that technologies developed by Russian scientists withstand the test of time successfully [4-6].

Currently, research in the area of artificial insemination of horses in Russia and abroad is carried out at a completely new level using the modern methods of computer analysis of semen, flow cytometry, transmission electron microscopy, etc. New technical opportunities have allowed scientists to delve deeper into the study of intracellular interactions and ultrastructural characteristics of germ cells in connection with cryostability and fertilizing capacity of sperm after freezing and thawing [7-10].

The unconditional advantages of AI compared to natural mating are fast selection effect, easy transportation, wide dissemination of valuable genetic material, economic use of semen and rational use of sires, prevention of sexually transmitted infections, reserving sperm prominent individuals and representatives of endangered breeds using cryobanks.

Dealing with frozen semen requires attention and care, as the qualitative characteristics of sperm are largely deteriorated as a result of cryopreservation stress. Insemination with such sperm reduces the pregnancy rate compared to fresh and cooled semen. According to foreign sources, the pregnancy rate in mares after insemination with frozen semen averages 35-50\% with the fluctuations of 31 to $73 \%$ in the first cycle [11]; in Russia, these figures are approximately the same $[12,13]$.

Among the factors influencing the result of $\mathrm{AI}$ in horse breeding are time, frequency rate and insemination repetition, quality and quantity of semen, the depth of insertion of semen into the uterus of a mare, the observance of temperature mode and sanitary regulations during AI procedures [14-18]. In addition, experts pay serious attention to the state of reproductive system of mares, especially after foaling, abortion, and in the presence of signs of abnormalities [14, 15, 19, 20] associated directly with pregnancy rates. Many foreign publications deal with the problem of mating-induced endometritis [11, 21, 22].

The main requirements on the quality of sperm after thawing are currently the following: semen activity at least 2.5 points, or $25 \%$ according to Russian standards [23, 24] and $30 \%$ according to foreign standards [19, 25, 26]; the number of spermatozoa with rectilinear translational motion (RTM) in the dose should not be less than 200-300 million $(12,19,25)$; in domestic technolo- 
gies of cryopreservation, quality indicators also include the survival of sperm of not less than 96 hours [23, 24].

Currently, there are two main approaches to freezing of stallion sperm and thus two AI technologies for semen packaging and equipment for its introduction into the uterus of mares. The first approach worked out and used in Russia is based on a sparing mode of semen cryopreservation in large volumes, 20-25 ml per dose [27]. The second method, developed abroad, provides pretreatment of sperm by centrifugation and maximum removal of semen plasma, i.e. the increase in spermatozoa content and reduction of the dose volume down to 1-6 $\mathrm{ml}[28,29]$. Under this approach, the so-called low volume foreign technologies also differ in the composition of diluents, cryoprotectants and methods of preparation of sperm for freezing. In other procedures used in Russia, small volumes $(5-6 \mathrm{ml})$ of semen are cryopreserved after centrifugation, removal of 50-60\% of semen plasma [30] and thickening semen by dialysis [31]. In the 1970s, a method of semen cryopreservation (without centrifugation) in granules [32] packaged in tubes with the final volume of $20-25 \mathrm{ml}$ per dose was developed in the USSR.

Depending on the method of cryopreservation, different types of semen packaging are provided: aluminum tubes of 5 and 15-25 $\mathrm{ml}$ (domestic technology) [27, 30, 31]; plastic straws of $0.25 ; 0.5$ and $5 \mathrm{ml}$ (foreign technology) [26, 29]. In the first option, one tube makes one dose for insemination, and in the second option, a dose may be from one straw of $5 \mathrm{ml}$ to 2-12 and more straws of 0.25 and $0.5 \mathrm{ml}$.

It should be emphasized that stallions are very strictly selected for semen cryopreservation abroad, despite the breeding value and the outstanding workability of procreaters. Therefore, all semen in straws in the international market usually has high quality indicators. There is no such choice of stallions in Russia, so our experts commissioned by horse owners sometimes have to work with the semen of lower quality to save valuable breed lines. Domestic technology [27] makes it possible as it lacks the centrifugation stage that reduces the damaging effect and keeps the fertilizing capacity of sperm to an acceptable level.

The issue of the optimal interval between insemination and ovulation is the cornerstone of any AI technology. Domestic and foreign recommendations for the use of cryopreserved semen are slightly different. For example, in Russia insemination of mares with frozen and thawed semen starts in the 3rd-4th degree of follicle maturity with an interval of 12-16 hours prior to the ovulation. Russian experts recommend not to inseminate mares after ovulation [14-17, 20, 24]. Abroad, mares are inseminated with frozen and thawed semen (based on rectal and ultrasound signs of approaching ovulation) no earlier than 12 hours prior to ovulation and not later than 6 hours after ovulation [11, 19, 25, 26, 33].

In comparing domestic and foreign approaches to cryopreservation of stallion semen and insemination of mares with frozen and thawed semen, their benefits and drawbacks should be highlighted. Semen thickening by centrifugation and semen packaging in straws or tubes of small volume makes it possible to store and transport a larger number of doses in Dewar flasks and saves liquid nitrogen. However, this approach requires a high quality of the original semen material and is associated with its loss during processing (removing the supernatant after centrifugation) and as a result with the increased amount of semen per dose. The domestic so-called large-volume technology $(15-25 \mathrm{ml})$ is more gentle, therefore allowing to work with the sperm of less quality and use the entire original amount of semen without loss. In terms of automation, computerization and full provision of the production process with specially developed tools, foreign technology can be probably preferred. However, the cost of production 
lines, dependence on imported media and consumables, as well as the need to create certain conditions for work limit their use to the scope of specialized reproductive centers or large studs. Simple and inexpensive domestic technology, on the contrary, makes it possible to successfully freeze stallion semen even at small private farms. Despite the above differences, both approaches are not inferior to each other in terms of semen quality after thawing and provide about the same performance in the artificial insemination of mares.

Stallion sperm, cryopreserved according to foreign technology, appeared in Russia fairly recently. The high cost of the semen (from some hundred to some thousand euros per one dose of 1.5-6 ml), expensive imported tools, lack of national experts with the necessary skills slow down the process of active introduction of foreign technology in the practice of Russian horse breeding. Therefore, it was not possible to collect credible data on the results of its use in our country until recently.

The purpose of this study was to analyze the indicators of mare reproduction after artificial insemination with semen frozen on different technologies, and figuring out the decisive factors.

Technique.. Experiments were carried out at the Tersk stud (Stavropol region), Mr. A.A. Kazakov's private farm (Ryazan region) and experimental stable of the All-Russian Research Institute for Horse Breeding in 2012 to 2014. Conditions and feeding conformed zootechnical standards at all farms. Stallion cryopreserved semen frozen on different technologies and with different activity, including the below the recommended ones, was used for insemination.

Mares of riding (Arabian, Akhal-Teke, Trakehner, Hanoverian, Russian Riding horse) and trotter (American Standardbred, Russian Trotter and Orlov Trotter) breeds were divided into groups based on the following factors: insemination with sperm in different packaging (granules, tubes, straws), insemination with sperm with different activity, time of insemination relative to ovulation, reproductive group of mares (barren and maiden, lactating, after a late abortion), initial gynecological state of mares (with no visible signs of abnormalities, with visible signs of abnormalities).

Semen packaging involves the technology of its cryopreservation. Semen doses frozen using three domestic technologies and semen of foreign production (Germany, France, Italy, and United States) were included in the experiments. For this purpose, semen packed in granules stored in the Cryobank of the Breeding Institute (according to E.M. Platonov's) (Group 1), in tubes of 15-25 ml (according to A.I. Naumenkov and N.K. Romanjkova) (Group 2), in tubes of $5 \mathrm{ml}$ (according to E.L. Fomina) (Group 3) was used. Imported semen (Group 4) in straws of $0.5 \mathrm{ml}$ (3 to 8 straws in a dose) was obtained from farms and private customers for the insemination of their mares.

Semen activity after thawing was determined using a standard method in accordance with the recommendations [24]. All used sperm doses (domestic and foreign) in various packages were divided into two groups with the activity of $\geq 1.5$ points and $<1.5$ points. Sperm samples with low activity cryopreserved according to the domestic technology, when compared with imported semen, were additionally combined into two subgroups with the activity above and below 2 points $(20 \%)$.

Follicle maturity was monitored by rectal and ultrasound diagnostics with an interval of 6 hours. The period recommended for artificial insemination with frozen semen was divided into three intervals (12 hours prior to ovulation, during ovulation, 6 hours after ovulation) and results of insemination were evaluated for each of them. Mares were inseminated using the appropriate tools. The result of insemination was determined using ultrasound diagnostics (from 
days 14-15 after ovulation) and rectal (from days 18-20 after ovulation) method. Pregnancy rates $(\%)$ and successful foaling $(\%)$ were registered based on the data for the year not only relative to the number of pregnant mares but also to the number of inseminated mares as the total measure of the breeding stock efficiency. Additionally, abortions (or cases of fetal death) were taken into account.

Three groups of mares were identified based on the functional state of their reproductive system: Group I - barren and maiden mares (mating for the first time), Group II - lactating mares (nursing), Group III - mares after late (6 or more months of pregnancy) abortion.

Mares were divided into two groups based on their gynecological statewith abnormalities and without abnormalities. Visible signs (diagnosed with rectal, ultrasound or vaginoscopic examinations) of abnormalities included vaginal discharge, fluid and air in the uterus, and mating-induced endometritis.

The data were processed by the conventional method of calculation of statistical characteristics evaluating the significance of intergroup differences using the Student-Fischer $t$-test (34).

Results. We processed the data of three breeding seasons of 106 estrus cycles (53 mares) when artificial insemination was carried out with cryopreserved semen, prepared by Russian and foreign technologies.

Comparison of the effectiveness of insemination with sperm in a different packaging showed that the pregnancy rate in the mares of Group 4 (straws of $0.5 \mathrm{ml}$ ) was similar to that in Group 1 (granules), but was significantly ( $\mathrm{p}<0.05)$ greater versus that in Group $2(5-25 \mathrm{ml}$ tubes) (Table 1$)$.

Since the activity of imported semen was never below 2-2.5 points, while in Group 2 it did not exceed 0.5 points in some cases, we divided Group 2 into two subgroups (with sperm activity above and below 2 points). As a result, the pregnancy rate in the subgroup with high semen quality increased to $69.6 \%$ and was no longer significantly different from that in Group 4, it dropped to $43.5 \%$ in the subgroup with semen activity of less than 2 points, but the differences between subgroups were not significant.

1. Results of artificial insemination (AI) of mares of riding and trotting breeds with cryopreserved sperm in various packaging and of unequal activity (Tersk stud, Mr. A.A. Kazakov's private farm, All-Russian Research Institute for Horse Breeding, 2012-2014)

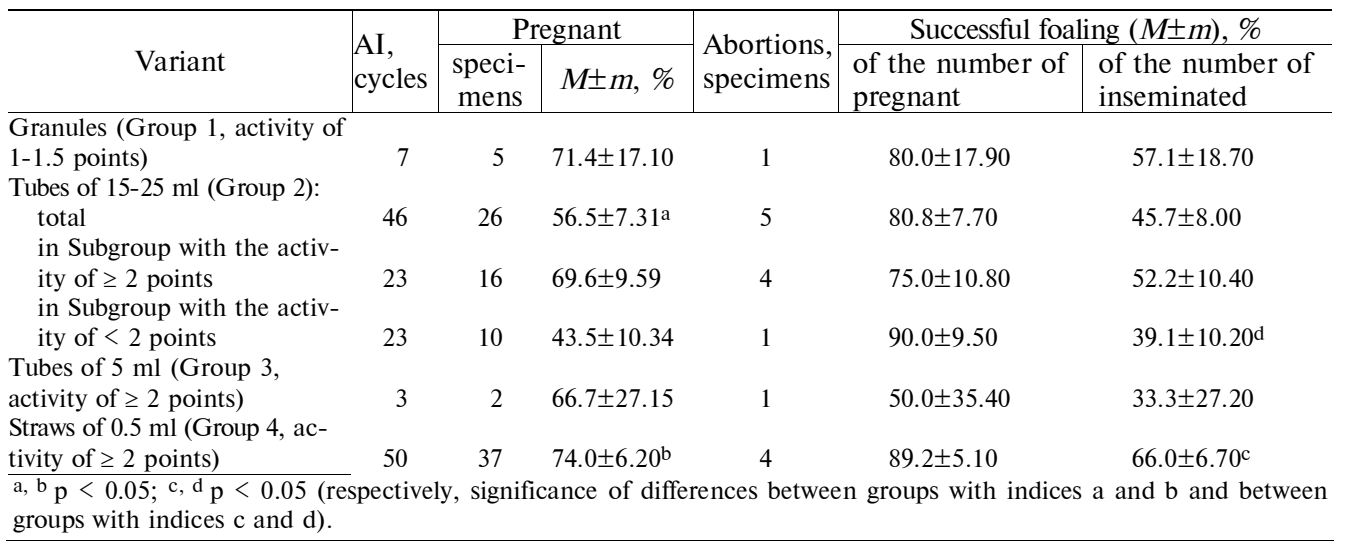

The percentage of successful foaling versus the number of inseminated mares had some tendency to increase in Group 4. It differed significantly $(p<0.05)$ from that in the subgroup with semen activity of $<2$ points. However, if the percentage of successful foaling relative to the number of pregnant mares is considered, the difference is leveled. Intergroup differences were insignificant 
in all other cases.

In general, the effectiveness of insemination of mares with semen frozen according to different technologies and packed in different containers (subject to the skilled procedure of insemination) ranged within 69-72\% and had no significant differences.

2. Results of artificial insemination (AI) of mares of riding and trotting breeds depending on the timing of insemination with cryopreserved sperm and its activity (Tersk stud, Mr. A.A. Kazakov's private farm, All-Russian Research Institute for Horse Breeding, 2012-2014)

\begin{tabular}{|c|c|c|c|c|c|}
\hline \multirow[b]{2}{*}{ AI, cycles } & \multicolumn{2}{|c|}{ Pregnant } & \multirow{2}{*}{$\begin{array}{l}\text { Abortions, } \\
\text { specimens }\end{array}$} & \multicolumn{2}{|c|}{ Successful foaling $(M \pm m), \%$} \\
\hline & specimens & $M \pm m, \%$ & & $\begin{array}{l}\text { of the number of } \\
\text { pregnant }\end{array}$ & $\begin{array}{l}\text { of the number of } \\
\text { inseminated }\end{array}$ \\
\hline \multicolumn{6}{|c|}{$\begin{array}{l}\mathrm{T} \text { i m e of i } \mathrm{n} \text { s e } \mathrm{m} \text { i } \mathrm{n} \text { a t i o } \mathrm{n} \\
12 \text { hours prior to ovulation }\end{array}$} \\
\hline \multicolumn{6}{|c|}{ During ovulation } \\
\hline \multicolumn{5}{|c|}{6 hours after ovulation } & $42.9 \pm 10.80$ \\
\hline \multicolumn{6}{|c|}{$\begin{array}{c}\mathrm{Sperm} \text { a c t ivit } \mathrm{y} \\
\geq 1.5 \text { points }\end{array}$} \\
\hline 59 & 46 & $78.0 \pm 5.40^{\mathrm{a}}$ & $\begin{array}{c}7 \\
1.5 \text { points }\end{array}$ & $84.8 \pm 5.30$ & $66.1 \pm 6.20^{\mathrm{c}}$ \\
\hline 28 & 5 & $17.9 \pm 7.20^{\mathrm{b}}$ & 1 & $80.0 \pm 17.90$ & $14.3 \pm 6.60^{d}$ \\
\hline
\end{tabular}

In comparing effectiveness depending on the time of insemination (12 hours prior to ovulation, during ovulation, 6 hours after ovulation) no significant differences in pregnancy rates were observed between variants (Table 2), and the average values were not beyond 52-68 \%. There were no significant differences in the percentage of successful foaling as well (see Table. 2). Meanwhile, it is well known that the timing of follicle maturation and ovulation in mares is often (especially in the spring transition period) unpredictable even for experts, so the attempts of insemination prior to ovulation are always followed by a risk to waste a semen dose at the price from 500-5,000 euros and above. The studies confirm high pregnancy rate in mares inseminated with single doses of sperm frozen in tubes and straws, within 6 hours after ovulation.

Analysis of pregnancy rates after insemination of mares with semen with the activity below and above 1.5 points $(15 \%)$ regardless of the type of packing (see Table 2) revealed highly significant intergroup differences $(\mathrm{p}<0.001)$. This means that semen quality affects the outcome of the procedure dramatically. Differences in the proportion of successful foalings versus the number of inseminated mares appeared to be significant as well $(\mathrm{p}<0.001)$. However, the abortion rate in the groups of pregnant mares was similar.

The functional state of the reproductive system of mares at the time of insemination is directly related to the conditions for the survival of semen and the embryos in the uterus and hormonal regulation of sexual function, and, consequently, may affect the pregnancy rate. However, significant differences between three reproductive groups in the pregnancy rate have not been identified (Table 3).

Although the pregnancy rate in Group III was $31.3 \%$ higher than that in group II, the number of mares in Group III, was probably not sufficient to consider such differences significant.

Insemination with and without signs of abnormalities of the reproductive system in mares revealed highly significant differences in subsequent pregnancy rate $(p<0.001)$ and successful foaling $(p<0.01)$ in favor of ani- 
mals with good reproductive health. However, the increased proportion of abortions in pregnant mares with abnormalities was not significantly confirmed despite the considerable difference of this value in healthy and problem mares.

3. Results of artificial insemination (AI) of mares of riding and trotting breeds depending on the reproduction group and their gynecological state (Tersk stud, Mr. A.A. Kazakov's private farm, All-Russian Research Institute for Horse Breeding, 2012-2014)

\begin{tabular}{|c|c|c|c|c|c|}
\hline \multirow[b]{2}{*}{ AI, cycles } & \multicolumn{2}{|c|}{ Pregnant } & \multirow{2}{*}{$\begin{array}{l}\text { Abortions, } \\
\text { specimens }\end{array}$} & \multicolumn{2}{|c|}{ Successful foaling $(M \pm m), \%$} \\
\hline & specimens & $M \pm m, \%$ & & $\begin{array}{l}\text { of the number of } \\
\text { pregnant }\end{array}$ & $\begin{array}{l}\text { of the number of } \\
\text { inseminated }\end{array}$ \\
\hline \multicolumn{6}{|c|}{$\begin{array}{l}\text { Re p r o d u c t i v e } \mathrm{grou} \mathrm{p} \\
\text { Group I (barren and maiden) }\end{array}$} \\
\hline 46 & \multicolumn{5}{|c|}{ Group II (lactating) } \\
\hline 25 & 13 & $\begin{array}{r}52.0 \pm 10.00 \\
\text { Group }\end{array}$ & $\begin{array}{c}1 \\
\text { (after late } a b\end{array}$ & (ion) $92.3 \pm 7.40$ & $48.0 \pm 10.00$ \\
\hline 6 & 5 & $83.3 \pm 15.23$ & 2 & $60.0 \pm 21.90$ & $50.0 \pm 20.40$ \\
\hline \multicolumn{6}{|c|}{$\begin{array}{c}\mathrm{G} \text { y } \mathrm{n} \text { e c o } 1 \text { o g i c a } 1 \text { s t a t e } \\
\text { No visible abnormalities }\end{array}$} \\
\hline 18 & 16 & $88.9 \pm 7.40^{\mathrm{a}}$ & 3 & $87.2 \pm 9.20$ & $72.2 \pm 10.60^{\mathrm{c}}$ \\
\hline \multicolumn{6}{|c|}{ Abnormalities (vaginal discharge, fluid and air in the uterus, mating-induced endometritis) } \\
\hline 18 & 7 & $38.9 \pm 11.50^{\mathrm{b}}$ & 3 & $57.1 \pm 11.70$ & $22.2 \pm 9.80^{\mathrm{d}}$ \\
\hline
\end{tabular}

Thus, two of the five factors analyzed, most important and determining the outcome of insemination with frozen semen can be identified. These are semen quality (activity of not less than 1.5 points) and the initial gynecological state of mares. Cryopreservation technology, the type of sperm doses' packaging and also the mare's reproductive status are of secondary importance subject to professional insemination. It is shown that mares' artificial insemination with one dose of semen within 6 hours after ovulation provides the same pregnancy rate as insemination within 12 hours prior to ovulation or at the time when the ovum is released from a follicle. This means rectal and ultrasound diagnosis of mare ovarian during maturation of the follicle can be limited to a 6-hour interval, and insemination should be immediately conducted in fact of ovulation. Such a regime saves the dose of expensive semen and ensures high pregnancy rates in mares.

\section{REFEREN CES}

1. I va nov I.I. Iskusstvennoe osemenenie $u$ mlekopitayushchikh [Artificial incemination in mammals]. St. Petersburg, 1907.

2. N a u m e n k ov a V.A., R o m a n' k ov a N.K. V sbornike dokladov nauchno-prakticheskoi konferentsii $i$ koordinatsionnogo soveshchaniya, posvyashchennykh 100-letiyu so dnya rozhdeniya P.N. Skatkina [In: Proc. Conf. and Meeting devoted to P.N. Skatkin's 100 anniversary]. Divovo, 2004.

3. G o tlib M.M., Ka la s h n k ov V.V. Konevodstvo i konnyi sport, 2011, 6: 22-23.

4. Naumenkova V.A., A troshchenko M.M., Lebedeva L.F., Khalilov R.A., R y a b o v a T.N. Konevodstvo i konnyi sport, 2013, 5: 15-17.

5. Kalashnikov V.V., Naumenkova V.A., Adamkovskaya M.V., Filimonova O.L. Zootekhniya, 2009, 2: 28-29.

6. Lebedeva L.F., Naumenkova V.A., At rosh chenko M.M. The scientific development in horse reproduction in Russia. Book of abstracts of the $64^{\text {th }}$ annual meeting of the European Federation of animal science (EAAP). Nantes, France, 2013: 131.

7. Kavak A., Johannisson A., Lundeheim N., Rodriguez-Martinez H., A id nik M., Ei n a rs s o n S. Evaluation of cryopreserved stallion semen from Tori and Estonian breeds using CASA and flow cytometry. Animal Reproduction Science, 2003, 76: 205216 (doi: 10.1016/S0378-4320(02)00247-6).

8. Pesch S., B ostedt H., Failing K., B ergmann M. Advanced fertility diagnosis in stallion semen using transmission electron microscopy. Animal Reproduction Science, 2006, 91: 285-298 (doi: 10.1016/j.anireprosci.2005.04.004). 
9. Atroshchenko M.M., Bragina E.E. Change in the ultrastructure of stallion spermatozoa under the effect of cryopreservation. Russian Agricultural Sciences, 2011, 37(2): 175-178 (doi: 10.3103/S1068367411020029).

10. Elkin a Yu.L., Atrosh chenko M.M., Bragina E.E., Muronetz V.I., Sch ma 1 $\mathrm{h}$ a u s e $\mathrm{n}$ E.V. Oxidation of glyceraldehydes-3-phosphate dehydrogenase decreases sperm motility. Biochemistry (Moscow), 2011, 76(2): 268-272 (doi: 10.1134/S0006297911020143).

11. Knottenbelt D.C., Pascoe R.R., Leblan c M., L o p a e Ch. Equine stud farm medicine and surgery. Elsevier Science Ltd., 2003.

12. N a u m e n k v a V.A. Materialy Mezhdunarodnoi nauchno-prakticheskoi konferentsii «Rol' $i$ znachenie metoda iskusstvennogo osemeneniya sel'skokhozyaistvennykh zhivotnykh $v$ progresse zhivotnovodstva 20-21 vekov» [In: Proc. Conf. «The role and importance of farm animals' artificial insemination in the kivestock progree in XX to XXI century»]. Dubrovitsy, 2004: 100-102.

13. N a u m e n k ov a V.A., V a s i l' e v a O.V. Zootekhniya, 2007, 5: 30-32.

14. Milova n ov V.K. Biologiya vosproizvedeniya $i$ iskusstvennoe osemenenie sel'skokhozyaistvennykh zhivotnykh [Reproductive biology and artificial insemuation of farm animals]. Moscow, 1962: 581-615.

15. O zh i n F.V., Rodin I.I., Rumyant s e v N.V., Skatk in P.N., S h e rgi n N.P. Iskusstvennoe osemenenie sel'skokhozyaistvennykh zhivotnykh [Artificial insemination of farm animals]. Moscow, 1961.

16. Z h i v o t k o v Kh.I. Konevodstvo, 1941, 2: 6.

17. K r a s n i k ov A.S. Konevodstvo [Horse-breeding]. Moscow, 1973.

18. S i e mea N., S chaferb T., S t outc T.A.E., K lugb E., Waberskid D. The effects of different insemination regimes on fertility in mares. Theriogenology, 2003, 60: 1153-1164 (doi: 10.1016/S0093-691X(03)00113-4).

19. M o t t e rs h e a d J. Frozen semen preparation and use. Part 1. "Canadian Morgan» Magazine, Nov/Dec 2000: 32-43.

20. Z h i v o t k ov Kh.I. Osnovy osemeneniya loshadei [Basics of the mares' insemination]. Moscow, 1952.

21. Py c o c k J.F., New c o m b e J.R The relationship between intraluminal uterine fluid, endometritis and pregnancy rate in the mare. Equine Practice, 1996, 18: 19-22.

22. Troeds s o n M.H.T. Uterine response to semen deposition in the mare. Proc. Annual Meeting of the Society for Theriogenology. USA, Texas, San Antonio, 1995: 130-135.

23. Sperma zherebtsov zamorozhennaya. GOST 24168-80 [Frozen semen of stallions. RF Standard 24168-80]. Moscow, 1980.

24. Instruktsiya po iskusstvennomu osemeneniyu i transplantatsii embrionov loshadei [Instructions on artificial insemination and embryo transfer in horses]. Divovo, 2013: 28-29.

25. S quires E.L., R e ge $\mathrm{r}$ H.P., M a c le 11 a n L.J., B rue m m e r J.E. Effect of time of insemination and site of insemination on pregnancy rates with frozen semen. Theriogenology, 2002, 58: 655-658.

26. L o o m is P.R. Storage, handling, and distribution of frozen equine semen. Proc. of the Annual Convention of the AAEP. San Diego, California, 2001, V. 47: 296.

27. N a umenkov A.I., Roman'kova N.K. Nauchnye trudy VNIIK, 1971, tom XXV: $128-132$.

28. L o o m is P.R., A man n R.P., S quires E.L., Pi ckett B.W. Fertility of unfrozen and frozen stallion spermatozoa extended in EDTA-lactose-egg yolk and packaged in straws. $J$. Anim. Sci., 1983, 56(3): 687-693.

29. M a rti n J.C. Centrifugation of stallion semen and its storage in large volume straws. J. Reprod. Fertil., 1979, 27: 47-51.

30. Fomina E.L. V sbornike nauchnykh trudov VNIIK: Puti uskoreniya nauchno-technicheskogo progressa $v$ konevodstve [In: Ways to accelerate scientific and technological progress in the horse breeding: scientific works of VNIIK]. Divovo, 1989: 65-66.

31. N a u m e n ov a V.A. Ispol'zovanie dializa dlya kriokonservatsii spermy zherebtsa. Kandidatskaya dissertatsiya [Dialysis in the stallions' semen cryopreservation. PhD Thesis]. Divovo, 1994.

32. Platov E.M., Pustovaya E.S., Lyalin A.D., Kotyag i na V.A. Nauchnye trudy VNIIK, 1971, tom XXV: 123-127.

33. Avanzi B.R., Ramos R.S., Araujo G.H.M., Fioratti E.G., Trinca L.A., D e 11 ' A qua J.A. Jr., M e lo e O na C.M., Z ahn F.S., Marti n I., Alvare nga M.A., $\mathrm{P}$ a p a F.O. Fixed-time insemination with frozen semen in mares: is it suitable for poorly fertile stallions? Theriogenology, 2015, 83(9): 1389-1393 (doi: 10.1016/j.theriogenology.2014.07.007).

34. Merkur'eva E.K. Biometriya $v$ selektsii $i$ genetike sel'skokhozyaistvennykh zhivotnykh [Biometry in bredding and genetics of farm animals]. Moscow, 1970: 226-237. 